\title{
Total laparoscopic hysterectomy for benign disease: outcomes and literature analysis
}

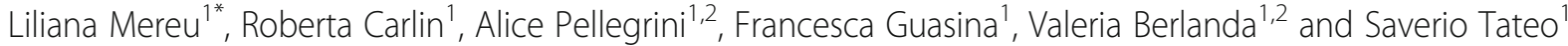

\begin{abstract}
Objective: To analyze surgical outcomes of total laparoscopic hysterectomy (TLH) for benign disease. Methods: Retrospective analysis of 361 consecutive cases, prospectively collected from January 2012 to June 2016, of women who underwent TLH in St. Chiara Hospital in Trento, Italy. Clinical, demographic, surgical, and intra and perioperative data were recorded. Complications were graded on the Clavien-Dindo morbidity scale. Data were compared with literature. Statistical analysis was performed with SPSS (SPSS Chicago, IL).

Findings: Main indication for TLH was uterine fibromatosis (78.6\%). Mean uterine size was $327 \pm 249 \mathrm{~g}$ (range 301800 g). Mean operating time was $115 \pm 36$ min. No laparotomy conversion occurred. Mean length of hospital stay was $2.6 \pm 1.1$ days (range $1-12$ days).

Complications requiring surgical intervention in general anesthesia occurred in 3 patients (0.8\%): 1 (0.3\%)

hydroureteronephrosis, 1 (0.3\%) bowel adhesions, and 1 (0.3\%) port side hernia; complication requiring surgical intervention without general anesthesia occurred in 6 patients (1.6\%): 2 (0.6\%) hydroureteronephrosis, 1 (0.3\%) vaginal cuff dehiscence, and $3(0.8 \%)$ vaginal cuff bleeding.
\end{abstract}

Conclusions: Total laparoscopic hysterectomy is a procedure with a low incidence of complications. Our data compare favorably with the data of the other listed studies.

Keywords: Total laparoscopic hysterectomy, Complications, Outcomes, Benign disease, Total hysterectomy

\section{Introduction}

Hysterectomy is the most frequent gynecological procedure performed, and in most cases, the laparoscopic approach may avoid the need for laparotomy.

The benefits of laparoscopic hysterectomy (LH) versus abdominal hysterectomy $(\mathrm{AH})$ are a quicker return to normal activities, a lower intraoperative blood loss, a smaller drop in hemoglobin, a shorter hospitalization, and less infections. The drawbacks are more injuries to the urinary tract and longer operation time [1]. However, the wider use of the laparoscopic approach and the improvement of surgeons' skills can decrease the incidence of complications [2]. The purpose of this study is to evaluate our total laparoscopic hysterectomy (TLH) surgical technique, analyzing the intra and postoperative surgical results and complications with a simple and

\footnotetext{
* Correspondence: liliana_mereu@yahoo.com

${ }^{1}$ Department of Gynecology and Obstetrics, St. Chiara Hospital of Trento,

Trento, Italy

Full list of author information is available at the end of the article
}

reproducible classification and to compare the results with data in the literature.

\section{Materials and methods}

This is a retrospective analysis of a prospectively collected database (Oxford CEBM level 3), conducted by the Department of Gynecology and Obstetrics of St. Chiara Hospital in Trento (Italy). The data concern a number of consecutive cases of women who underwent TLH between January 2012 and June 2016.

The data on the patient's age, body mass index (BMI), parity, comorbidities, menopause status, previous surgery, surgical indication, surgical procedures, uterine weight, and intra and postoperative outcomes (duration of procedure, blood loss, hospital stay, and complications) were collected in a database. The duration of procedure was calculated from the beginning to the end of surgery, and the concomitant surgical procedures were included. 
Inclusion criteria are as follows: age $>18$ years, signed written informed consent, uterine benignant disease, and indication for laparoscopic hysterectomy.

Exclusion criteria were malignant disease, adnexal pathology with suspicion of malignancy, genital prolapse, and contraindications to laparoscopy. Patients were subsequently examined 4 to 6 weeks after surgery and if needed even before or after. Patient's clinical data were collected from the hospital clinical database: SIO (Sistema Informatico Ospedaliero); exams, hospitalization, and visits performed in the district are available for a follow-up period of 6 months. Patient's consensus was asked during the hospitalization.

Ethical approval for the study was obtained from the Institutional Review Board.

Surgeries were performed by two expert surgeons (ST and LM).

\section{TLH surgical technique}

Before surgery, patients underwent routine examinations, including blood tests, gynecological examination, gynecological ultrasound scanning, and endometrial biopsy. Patients received antibiotic prophylaxis (with cephalosporin given following anesthetic induction) and thromboprophylaxis with low molecular weight heparin. All patients were routinely catheterized at the beginning of operation, with the catheter being removed the day after, as soon as the patient could independently reach the toilet. Bladder was filled with $20 \mathrm{ml}$ of Sodium Indigotin Disulfonate $40 \mathrm{mg} / 10 \mathrm{ml}$ diluted in $250 \mathrm{ml}$ of saline. The patient was placed in supine position under endotracheal general anesthesia. The abdomen and vagina were disinfected. The patient was draped and placed in the Trendelenburg position. The peritoneum entry was performed with a modified open technique or with a Veress needle. The surgical technique follows the one described by Clermont-Ferrand [3] using cold scissors, bipolar forceps, and the Hohl uterine manipulator (Karl Storz GmbH, Tuttlingen, Germany). In case of large uterus, until 2015, the organ was vaginally removed after cold blade laparoscopic morcellation, since 2015 vaginal morcellation of the uterus inside an endobag was undertaken. In case of big uterus that did not fit into the endobag, a minilaparotomy for extraction was performed. In most cases, suture was performed using barbed suture or polyglactin $2 / 0$ interrupted suture. TLH with bilateral salpingo-ovariectomy was suggested to menopausal patients, and prophylactic bilateral salpingectomy was offered to the other patients.

\section{Classification of complications}

Complications were recorded and divided into intraoperative and postoperative and further distinguished according to the structure involved.
Each postoperative complication was graded on the Clavien-Dindo 5-grade morbidity scale [4]. Grade I: any deviation from the normal postoperative course not requiring therapy (allowed therapeutic regimens are drugs as antiemetics, antipyretics, analgesics, diuretics, electrolytes, and physiotherapy, wound infections opened at the bedside). Grade II: issues requiring pharmacological treatment with drugs other than those allowed for grade I complications. Blood transfusions and total parenteral nutrition are also included. Grade III: issues requiring surgical, endoscopic, or radiological intervention. Grade IIIA: issues requiring intervention not under general anesthesia. Grade IIIB: issues requiring intervention under general anesthesia. Grade IV: life-threatening complication (including CNS complications) requiring IC/ICU management. Grade IVA: single organ dysfunction (including dialysis). Grade IVB: multiorgan dysfunction. Grade V: death of the patient. The time of occurrence of complication was indicated with " $D$ " if it occurred after discharge, "E" if it had an early onset ( $<30$ days), and " $L$ " if it had a late onset ( $\geq 30$ days).

\section{Statistical analysis}

Statistical analysis was performed with SPSS (SPSS Chicago, IL).

Normally distributed data are presented as mean \pm SD, and skewed data as median (range). Categorical variables are reported as absolute values and percentages. Categorical variables were compared using the $X^{2}$ test. $P$ values $<.05$ were considered to be statistically significant.

\section{Literature analysis}

Studies were selected from a literature analysis, exploring the PubMed database with a combination of the keywords "hysterectomy," "laparoscopic," "total laparoscopic," "complication," and "outcome"; cases dealing with total laparoscopic hysterectomy were selected. We took into consideration studies published after 2007 on total laparoscopic hysterectomy for benign disease, with a number of patients $\geq 200$ and considering overall complications, including all uterus weights and patients' characteristics.

\section{Results}

The baseline characteristics of 361 women who underwent TLH are summarized in Table 1. Indication for TLH was uterine symptomatic fibromatosis in 284 (78.7\%) patients, metrorrhagia in $19(5.2 \%)$ patients, endometrial hyperplasia with atypia $31(8.5 \%)$ patients, endometrial hyperplasia without atypia in $6(1.7 \%)$ patients, CIN 3 in 2 $(0.3 \%)$ patients, adenomyosis in $9(2.5 \%)$, and other indications in 14 (3.9\%) patients. Seventy-six out of 361 patients (21.1\%) were menopausal, and the surgical indications for TLH in this subgroup were 37 symptomatic myomas, 28 endometrial hyperplasia, 2 CIN3, and 9 other conditions. 
Table 1 Characteristics of patients $(n=361)$

\begin{tabular}{ll}
\hline Characteristics & Data \\
\hline Age, years & $49.6 \pm 6.5$ (37-83) \\
Comorbidity & $14(3.9)$ \\
Diabetes & $61(16.9)$ \\
Hypertension & $34(9.4)$ \\
Smoke & $11(3.0)$ \\
Cardiopathy & $25.8 \pm 5.6(17-51)$ \\
Body mass index & $76(21.1)$ \\
Menopause & \\
Previous abdominal surgery & \\
Laparoscopy & \\
1 & $61(16.9)$ \\
$\geq 2$ & $9(2.5)$ \\
Laparotomy & \\
1 & $127(35.2)$ \\
$\geq 2$ & $22(6.1)$
\end{tabular}

Values are given as mean \pm SD (range) or number (percentage) unless stated otherwise

Abbreviation: $B M I$ body mass index (calculated as weight in kilograms by the square of height in meters)

Table 2 describes intraoperative outcomes. No conversion to laparotomy for complication occurred. There were 2 (0.6\%) intraoperative complications: $1(0.3 \%)$ blood transfusion and $1(0.3 \%)$ bladder injury. Postoperative complications are described in Table 3. Mean hospital stay was $2.6 \pm$ 1.1 days. Postoperatively, complication grade V (death) or

Table 2 Intraoperative outcomes $(n=361)$

\begin{tabular}{ll}
\hline Outcomes & Data $^{\mathrm{a}}$ \\
\hline Mean operating times, min & $113 \pm 36(45-240)$ \\
Mean blood loss, ml & $44 \pm 79\left(10-500^{\mathrm{c}}\right)$ \\
Mean uterine size, g & $327 \pm 249(30-1800)$ \\
Morcellement & $198(54.8)$ \\
Minilaparotomy & $3(0.8)^{\mathrm{d}}$ \\
Complications & \\
Bladder injury & $1(0.3)$ \\
Blood transfusion & $1(0.3)^{\mathrm{c}}$ \\
Concomitant procedure & \\
Bilateral salpingectomy & $211(58.4)$ \\
Bilateral annessectomy & $118(32.7)$ \\
Lysis of adhesions & $70(19.4)$ \\
Ovarian cyst enucleation & $19(5.3)$ \\
Other surgical procedure & $23(6.4)$ \\
\hline
\end{tabular}

${ }^{a}$ Values are given as mean \pm SD (range) or number (percentage) unless stated otherwise

bIncluded: mammary nodule removal, colecystectomy, endometriosis heradication, and hernioplasty

'Uterus weight $1800 \mathrm{mg}$ and preoperative anemia

${ }^{\mathrm{d}}$ To remove surgical pieces grade IV (life-threatening complication) did not occur. There were $3(0.8 \%)$ grade IIIB complications that arose after discharge: 1 hydroureteronephrosis, 1 port side hernia, and 1 bowel adhesions. 6 (1.7\%) grade IIIA complications occurred after discharge: 1 vaginal cuff dehiscence, 3 vaginal cuff bleeding, and 2 hydrouretheronephosis (Table 3 ).

\section{Results of literature analysis}

Six studies with TLH population have been selected from the literature analysis: Kim et al. [5], Wallwiener et al. [6], Twijnstra et al. [7], Boosz et al. [8], Morelli et al. [9], and $\mathrm{Ng}$ et al. [10]. Table 4 shows the comparison of intraoperative outcomes while Table 5 shows intra and postoperative findings.

\section{Discussion}

Laparoscopy has been performed in gynecological surgery for more than 20 years, and its use is increasing. In most countries, the proportion of LHs has gradually increased over the years [1].

Many classifications of laparoscopic hysterectomy have been proposed, the most used being the 2003 one by Reich [11], which divides the laparoscopic hysterectomy procedure into LAVH (laparoscopically assisted vaginal hysterectomy), LH (laparoscopic hysterectomy), and TLH (total laparoscopic hysterectomy), the latter being when the entire operation is performed laparoscopically, with no vaginal component except the removal of the uterus. However, some authors have described the total laparoscopic hysterectomy technique with suture of the cuff by vaginal route [12]. This variety of techniques and definitions, added to the different stratification classifications of complications in various studies, makes it difficult to compare data in literature.

For these reasons, we decided to (1) include in this study only TLH with suture of the vaginal vault by laparoscopic approach, (2) use the Clavien-Dindo morbidity scale, which is a reproducible simple system to grade complications, based on the therapy required to treat them, (3) select from the TLH literature only recent studies published after 2007, and with a sizable number of patients (>200). The present study includes 361 consecutive patients who underwent laparoscopic hysterectomy for benign disease and is one of the largest monocentric series present in the literature. Analyzing patients' characteristic, the mean BMI of the patients of the present study (25.8) was in line with that of the majority of the other studies [5-9], as only the series of $\mathrm{Ng}$ et al. had a quite low BMI: 19.2 [10].

A large number of women included in the study had undergone previous laparotomy $(41.3 \%)$ and $24.1 \%$ one or more previous cesarean section. Previous abdominal surgery is no longer a contraindication to the laparoscopic 
Table 3 Postoperative complications (graded by Dindo-Clavien score)

\begin{tabular}{|c|c|c|}
\hline Dindo-Clavien score & Description & $N$, onset time \\
\hline \multirow[t]{3}{*}{$\mathrm{IIIB}$} & $\begin{array}{l}\text { Hydroureteronephrosis } \\
\text { Pre-discharge } \\
\text { Post-discharge }\end{array}$ & $\begin{array}{l}1 \\
0 \\
1, E\end{array}$ \\
\hline & $\begin{array}{l}\text { Port side hernia } \\
\text { Pre-discharge } \\
\text { Post-discharge }\end{array}$ & $\begin{array}{l}1 \\
0 \\
1, L\end{array}$ \\
\hline & $\begin{array}{l}\text { Bowel adhesions } \\
\text { Pre-discharge } \\
\text { Post-discharge }\end{array}$ & $\begin{array}{l}1 \\
0 \\
1, L\end{array}$ \\
\hline Total & & $3(0.8)$ \\
\hline \multirow[t]{3}{*}{$\| I A$} & $\begin{array}{l}\text { Vaginal cuff bleeding } \\
\text { Pre-discharge } \\
\text { Post-discharge }\end{array}$ & $\begin{array}{l}3 \\
0 \\
3, E\end{array}$ \\
\hline & $\begin{array}{l}\text { Vaginal cuff dehiscence } \\
\text { Pre-discharge } \\
\text { Post-discharge }\end{array}$ & $\begin{array}{l}1 \\
0 \\
1, E\end{array}$ \\
\hline & $\begin{array}{l}\text { Hydroureteronephrosis } \\
\text { Pre-discharge } \\
\text { Post-discharge }\end{array}$ & $\begin{array}{l}2 \\
0 \\
2,(1 E, 1 L)\end{array}$ \\
\hline Total & & $6(1.6)$ \\
\hline \multirow[t]{7}{*}{$\|$} & $\begin{array}{l}\text { Urinary infection } \\
\text { Pre-discharge } \\
\text { Post-discharge }\end{array}$ & $\begin{array}{l}14 \\
5, E \\
9, E\end{array}$ \\
\hline & $\begin{array}{l}\text { Vaginal cuff hematoma } \\
\text { Pre-discharge } \\
\text { Post-discharge }\end{array}$ & $\begin{array}{l}1 \\
0 \\
1, E\end{array}$ \\
\hline & $\begin{array}{l}\text { Cardiac arrhythmia } \\
\text { Pre-discharge } \\
\text { Post-discharge }\end{array}$ & $\begin{array}{l}2 \\
2, E \\
0\end{array}$ \\
\hline & $\begin{array}{l}\text { Pelvic abscess } \\
\text { Pre-discharge } \\
\text { Post-discharge }\end{array}$ & $\begin{array}{l}1 \\
0 \\
1, E\end{array}$ \\
\hline & $\begin{array}{l}\text { Wound infection } \\
\text { Pre-discharge } \\
\text { Post-discharge }\end{array}$ & $\begin{array}{l}4 \\
0 \\
4, E\end{array}$ \\
\hline & $\begin{array}{l}\text { Vaginal cuff infection } \\
\text { Pre-discharge } \\
\text { Post-discharge }\end{array}$ & $\begin{array}{l}4 \\
0 \\
4(2 E-2 L)\end{array}$ \\
\hline & $\begin{array}{l}\text { Postoperative blood transfusion } \\
\text { Pre-discharge } \\
\text { Post-discharge }\end{array}$ & $\begin{array}{l}2 \\
1, E \\
1, E\end{array}$ \\
\hline Total & & $28(7.8)$ \\
\hline \multirow[t]{3}{*}{ I } & $\begin{array}{l}\text { Wound hematoma } \\
\text { Pre-discharge } \\
\text { Post-discharge }\end{array}$ & $\begin{array}{l}2 \\
2, E \\
0\end{array}$ \\
\hline & $\begin{array}{l}\text { Paresthesia } \\
\text { Pre-discharge } \\
\text { Post-discharge }\end{array}$ & $\begin{array}{l}3 \\
1, E \\
2, E\end{array}$ \\
\hline & $\begin{array}{l}\text { Vaginal cuff bleeding } \\
\text { Pre-discharge } \\
\text { Post-discharge }\end{array}$ & $\begin{array}{l}4 \\
0 \\
4(3 E-1 L)\end{array}$ \\
\hline
\end{tabular}

Table 3 Postoperative complications (graded by Dindo-Clavien score) (Continued)

\begin{tabular}{lll}
\hline Dindo-Clavien score & Description & N, onset time \\
\hline & Vaginal cuff dehiscence & 2 \\
& Pre-discharge & 0 \\
& Post-discharge & $2, \mathrm{E}$ \\
& Wound dehiscence & 4 \\
& Pre-discharge & 0 \\
Post-discharge & $4, \mathrm{E}$ \\
& Wound infection & 1 \\
& Pre-discharge & 0 \\
& Post-discharge & $1, \mathrm{~L}$ \\
Total & & $16(4.4)$ \\
\hline
\end{tabular}

Values are given as number (percentage) unless stated otherwise

$E$ early onset $(<30$ days), $L$ late onset ( $\geq 30$ days)

approach, even if number of previous caesarian sections could be a risk factor for bladder lesions [13].

The surgical approach to hysterectomy as well as the average weight of uteri removed by laparoscopic approach still depends on the surgeon. The proportion of AH compared to LH for benign disease in our department was $8.6 \%$. The value is not reported in the studies selected, but it can vary considerably, from $2-5 \%$ [14] to $64 \%$ [15]. The average weight of the uteri removed was $327 \mathrm{~g}$; this value is higher (more than $60 \mathrm{~g}$ ) than the mean uterus weight reported by other authors $(217-259 \mathrm{~g})$ [5-8]. For this reason, morcellation with laparoscopic cold knife was necessary in $54.8 \%$ of cases, to remove the uterus.

The literature shows a prevalence of uterine sarcoma in presumed uterine fibroids from 0.00 to $0.49 \%$ [16]. In the present, the incidence of incidentally diagnosed sarcoma was $0.8 \%$ : 2 leiomyosarcomas and 1 endometrial stromal sarcoma. Even if the comparisons of the different study populations in the literature is difficult, one hypothesis to explain this finding could be that,as myoma size is considered a risk factor for sarcoma, in the present study, the mean weight and related size of the removed uteri is higher than those reported by other studies on hysterectomy and prevalence of uterine sarcoma.

Mean operative time was 113 min, which is comparable to other series [6-8] despite a higher mean uterine weight. It is quite longer if we consider two reference centers for laparoscopic surgery, with a mean operative time of 90 and $80 \mathrm{~min}[17,18]$.

All the procedures in the present series were performed by two senior surgeons adopting the TLH technique described by Wattiez et al. [19] that requires a uterine manipulator to reduce ureteral injury and to facilitate a correct exposition of the pelvis area: pouch of Douglas, posterior fornix, and uterine vessels.

Concerning the hospitalization time, our data favorably compare with literature $[5,6,9,10]$; however, hospital stay does not always reflect the postoperative course, since it is often influenced by rules related to 
Table 4 Comparison with literature: baseline characteristics

\begin{tabular}{llllllll}
\hline Authors & N.Pt & & $\begin{array}{l}\text { Mean age } \\
(\text { year) }\end{array}$ & Mean BMl & $\begin{array}{l}\text { Mean uterus weight } \\
(\mathrm{g})^{\mathrm{a}}\end{array}$ & $\begin{array}{l}\text { Mean operative time } \\
\text { (min) }^{\mathrm{a}}\end{array}$ & $\begin{array}{l}\text { Mean hospital stay } \\
\text { (days) }^{\mathrm{a}}\end{array}$ \\
\hline Kim 2015 [5] & 366 & Retrospective study & $47.7 \pm 7.4$ & $24.9 \pm 2.6$ & $259 \pm 149$ & $149.3 \pm 59$ & $5.5 \pm 2.0$ \\
Wallwiener 2013 [6] & 294 & Prospective study & $48.4 \pm 8.5$ & $25.6 \pm 5.1$ & $220 \pm 205$ & $103 \pm 36$ & $4.9 \pm 2.8$ \\
Twijnstra 2012 [7] & 960 & Cohort analysis & $48.8 \pm 11.3$ & $27.5 \pm 5.7$ & $217 \pm 196$ & $118 \pm 40$ & - \\
Boosz 2011 [8] & 567 & Retrospective study & $47.9 \pm 9.1$ & $26.2 \pm 5.3$ & $243 \pm 198$ & $104 \pm 44$ & - \\
Morelli 2007 [9] & 200 & Randomized trial & $41.2 \pm 4.4$ & $26.3 \pm 3.7$ & - & $86 \pm 3$ & $2.9 \pm 1.4$ \\
Ng 2007 [10] & 435 & Retrospective study & $47.5(34-72)^{\mathrm{b}}$ & $19.2(12-34)^{\mathrm{b}}$ & - & $136(40-257)^{\mathrm{b}}$ & $2.7(1-20)^{\mathrm{bc}}$ \\
Present study & 361 & Prospective study & $49.6 \pm 6.5$ & $25.8 \pm 5.6$ & $327 \pm 249$ & $113 \pm 36$ & $2.6 \pm 1.1(1-12)^{\mathrm{b}}$ \\
\hline
\end{tabular}

\section{${ }^{\mathrm{a}}$ Mean $\pm \mathrm{SD}$}

${ }^{\mathrm{b}}$ Mean (range)

'Data considered for 427 patients with a successful TLH (no laparotomy conversion)

${ }^{\mathrm{d}}$ Retrospective analysis of a prospective collected database

economic aspects, department procedures, territory, and patient's expectations. In many countries, early discharge policies are implemented and there are several studies of total laparoscopic hysterectomies performed in Day Surgery with analgesic therapy after discharge [20].

Only $2(0.6 \%)$ intraoperative complications occurred: 1 bladder injury $(0.3 \%)$ recognized and sutured during the intervention with a good outcome and $1(0.3 \%)$ blood transfusion (uterus weight of $1800 \mathrm{~g}$ ) due to intraoperative blood loss of $500 \mathrm{ml}$ and preoperative anemia $(\mathrm{Hb} 9.2 \mathrm{~g} / \mathrm{dl})$.

In the majority of the studies in the literature, the intraoperative complications are not taken into account as a specific group and these in the overall record of complications. An unrecognized intraoperative minor complication could become a postoperative major complication requiring reintervention. For this reason, even if the risk of intraoperative complications is very low $(0.6 \%)$, routinely filling the bladder with Sodium Indigotin Disulfonate is a cost-effective procedure in case of total hysterectomy.

There were $3(0.8 \%)$ grade IIIB complications, these arose after discharge. A ureteral occlusion appeared early with fever and hydroureteronephrosis in a patient who had undergone TLH for acute urine retention caused by a very large fibroma. This was treated with ureteral replanting. A late onset port side hernia required a hernioplasty procedure and late onset bowel adhesions required a laparoscopic lysis.

Grade IIIA complications occurred in $6(1.7 \%)$ patients after discharge: an early vaginal cuff dehiscence was solved with outpatient positioning of stitches, 3 early vaginal cuff bleeding, 2 of which required readmissions and 1 that required blood transfusion and 2 ureteral occlusions that were treated uneventfully with the endoscopic positioning of a double J catheter. No ureteral fistula occurred.

The majority of complications (35/53: 66.3\%) arose after discharge, within 1 month after surgery; during the recovery in the postoperative period 11 (20.8\%), complication occurred: 5 urinary infections, 2 cardiac arrhythmias, and 1 anemia, resolved with medical treatment.

The Clavien-Dindo score is also useful to categorize the "minor" complications in a more detailed way, as is important in a controlled clinical activity.

In our series, $28(7.8 \%)$ patients required additional medical treatment for postoperative complications and $16(4.4 \%)$ patients had mild postoperative conditions

Table 5 Comparison with literature: intraoperative and postoperative complications

\begin{tabular}{|c|c|c|c|c|c|c|c|c|c|c|}
\hline & $\begin{array}{l}\text { Bladder } \\
\text { injury }^{a}\end{array}$ & $\begin{array}{l}\text { Ureteral } \\
\text { Injury }^{a}\end{array}$ & $\begin{array}{l}\text { Bowel } \\
\text { injury }\end{array}$ & $\begin{array}{l}\text { Vascular } \\
\text { injury }^{\mathrm{a}}\end{array}$ & $\begin{array}{l}\text { Vaginal cuff } \\
\text { dehiscence }^{a}\end{array}$ & $\begin{array}{l}\text { Mini } \\
\text { laparotomy }\end{array}$ & Laparotomy $^{\mathrm{a}}$ & $\begin{array}{l}\text { Total } \\
\text { laparotomies }\end{array}$ & $\begin{array}{l}\text { Blood } \\
\text { transfusion }\end{array}$ & Reoperation $^{a}$ \\
\hline Kim 2015 [5] & $4(1.1)$ & $5(1.4)$ & $3(0.8)$ & $0(0)$ & $9(2.5)$ & $0(0)$ & $17(4.6)^{*}$ & $17(4.6)^{*}$ & & - \\
\hline Wallwiener 2013 [6] & $0(0)$ & $0(0)$ & $0(0)$ & $1(0.3)$ & $2(0.7)$ & - & - & $19(6.5)^{*}$ & - & $19(6.4)^{c, *}$ \\
\hline Twijnstra 2012 [7] & $13(1.4)$ & $4(0.4)$ & $5(0.5)$ & $1(0.1)$ & - & - & - & $46(4.8)^{*}$ & - & $15(1.6)$ \\
\hline Boosz 2011 [8] & $4(0.7)$ & $1(0.2)$ & $1(0.2)$ & - & $4(0.7)$ & $1(0.2)$ & $0(0)$ & $1(0.2)$ & - & $10(1.8)$ \\
\hline Morelli 2007 [9] & $7(3.5)^{*}$ & $5(2.5)$ & $1(0.5)$ & - & - & - & - & $10(5)^{*}$ & $14(7.0)^{*}$ & $2(1)$ \\
\hline $\mathrm{Ng} 2007$ [10] & $1(0.2)^{b}$ & $1(0.2)^{b}$ & $4(0.9)^{b}$ & $0(0)^{b}$ & $0(0)$ & $3(0.7)$ & $5(1.1)$ & $8(1.8)$ & $17(4.0)^{b, *}$ & - \\
\hline Present study & $1(0.3)$ & $1(0.3)$ & $0(0)$ & $0(0)$ & $0(0)$ & $3(0.8)$ & $0(0)$ & $3(0.8)$ & $3(0.8)$ & $4(1.1)^{d}$ \\
\hline
\end{tabular}

${ }^{a}$ Values are given as number (percentage) unless stated otherwise

${ }^{b}$ Data considered for 427 patients with a successful TLH (no laparotomy conversion)

'Operations for pelvic abscess, pelvic peritonitis, or hematoma are included

${ }^{\mathrm{d}}$ Reoperation for bowel adhesions and port side hernia are included

*The difference with the data of the present study is statistically significant $(p<0.05)$ 
that required treatment, mostly conservative, visits, or unplanned medications.

In the literature, complications are frequently classified as "major" or "minor," although this can lead to subjective interpretations, with a tendency to underestimate the event.

To compare our data with the literature, we had to consider major complications grouped by the organ involved. Our data compare favorably with those reported in the literature.

In the present study, we had only 1 bladder lesion $(0.3 \%)$, in line with the data reported by other authors [58, 10, 17, 21] except for Morelli et al. [9], that reported a significantly higher percentage $(3.5 \%)$ of bladder injury, probably related to the high numbers of patients with previous cesarean section $(>50 \%)$.

Ureteral injuries occurred in 3 cases $(0.8 \%)$, just 1 of them needing surgical intervention $(0.3 \%)$; these data are in line with those reported in the other series [5-10] and with the gynecological laparoscopic literature $[17,21]$.

Vaginal vault complications in laparoscopic surgery may occur, even though they are rare [22]. It is believed that the risk of vaginal cuff dehiscence is correlated to the chosen approach to hysterectomy and to suture. The suture of the cuff by vaginal route is associated with a lower risk of complications and a shorter operative time [23]. However, different sutures laparoscopically performed can differ in operative time and complications [14]. In our series, in 83.3\% of cases, a laparoscopic vaginal cuff closure has been performed with a continuous barbed suture; we identified $7(1.9 \%)$ cases of bleeding and $3(0.8)$ cases of dehiscence, 4 (1.1\%) requiring reintervention without general anesthesia, while $6(1.6 \%)$ had complications that were considered minor and did not require any medical or surgical intervention. These findings are in line with the $0-3.3$ percentage of dehiscence reported in recent suture dehiscence literature [24, 25]. Regarding vaginal bleeding: 3 major $(0.8 \%)$ and 4 minor (1.1\%) instances were recorded, with a prevalence in the present study comparable with those reported in the literature: 1.4-32.5 [15] and even lower considering that the majority of the studies do not consider Clavien-Dindo grade 1 vaginal bleeding.

Conversion to laparotomy due to complications or surgical difficulties did not become necessary. A minilaparotomy to remove the calcific specimen was necessary in 3 cases $(0.8 \%)$. Data from similar series $[5-7,9,10]$ revealed a mean rate of conversion of $4.5 \%$ (range 1.8$6.5 \%$ ) while Boosz et al. reported a percentage of conversion of $0.2 \%$ [8]. Blood transfusion was necessary in only $3(0.8 \%)$ cases evidencing a statistical significant difference in comparison with the $7 \%$ rates reported by Morelli et al. [9] and the 3\% by Ng et al. [10].

\section{Conclusion}

This study confirmed that total laparoscopic hysterectomy is a procedure with a low incidence of complications. Moreover, the technological evolution of the last few years, in terms of type of endoscope, multifunctional instruments, ultra MinInvasive accesses, and the possibility of completing courses in surgical technique and anatomy, have allowed its large-scale diffusion, extending its indications to difficult cases in a frail older population, with improvements also in term of indirect health costs.

\section{Abbreviations \\ AH: Abdominal hysterectomy; BMI: Body mass index; LAVH: Laparoscopically assisted vaginal hysterectomy; LH: Laparoscopic hysterectomy; TLH: Total laparoscopic hysterectomy \\ Acknowledgements \\ None \\ Funding \\ None \\ Availability of data and materials \\ Yes. \\ Authors' contributions \\ LM is a surgeon who supervised the study. RC analyzed the data and wrote the article. AP collected the data. FG analyzed the data and revised the final version of the article. VB collected the data and wrote the article. ST is a surgeon who analyzed the data and provided the original idea. All authors read and approved the final manuscript.}

Ethics approval and consent to participate

Ethical approval is not required for a restrospective study.

Consent for publication

Yes.

Competing interests

The authors declare that they have no competing interests.

\section{Publisher's Note}

Springer Nature remains neutral with regard to jurisdictional claims in published maps and institutional affiliations.

\section{Author details}

${ }^{1}$ Department of Gynecology and Obstetrics, St. Chiara Hospital of Trento, Trento, Italy. ${ }^{2}$ Department of Gynecology and Obstetrics, University of Verona, Verona, Italy.

Received: 21 April 2018 Accepted: 24 October 2018

Published online: 14 November 2018

References

1. Aarts JW, Nieboer TE, Johnson N, Tavender E, Garry R, Mol BW et al (2015) Surgical approach to hysterectomy for benign gynaecological disease. Cochrane Database Syst Rev:CD003677 0.1002/14651858.CD003677

2. Mäkinen J, Brummer T, Jalkanen J, Heikkinen AM, Fraser J, Tomás E et al (2013) Ten years of progress improved hysterectomyoutcomes in Finland1996-2006: a longitudinal observation study. BMJ Open 3(10):28

3. Velemir L, Azuar AS, Botchorishvili R, Canis M, Jardon K, Rabischong B et al (2009) Optimizing the role of surgeons assistants during a laparoscopic hysterectomy. Gynecol Obstet Fertil 37:74-80

4. Clavien PA, Sanabria JR, Strasberg SM (1992) Proposed classification of complications of surgery with examples of utility in cholecystectomy. Surgery 111:518-526

5. Kim SM, Park EK, Jeung IC, Kim CJ, Lee YS (2015) Abdominal, multi-port and single-port total laparoscopic hysterectomy: eleven-year trends comparison 
of surgical outcomes complications of 936 cases. Arch Gynecol Obstet 291: 1313-1319

6. Wallwiener M, Taran FA, Rothmund R, Kasperkowiak A, Auwärter G, Ganz A (2013) Laparoscopic supracervical hysterectomy (LSH) versus total laparoscopic hysterectomy (TLH): an implementation study in 1,952 patients with an analysis of risk factors for conversion to laparotomy and complications, and of procedure-specific re-operations. Arch Gynecol Obstet 288:1329-1339

7. Twijnstra AR, Blikkendaal MD, van Zwet EW, van Kesteren PJ, de Kroon CD, Jansen FW (2012) Predictors of successful surgical outcome in laparoscopic hysterectomy. Obstet Gynecol 119:700-708

8. Boosz A, Lermann J, Mehlhorn G, Loehberg C, Renner SP, Thiel FC (2011) Comparison of re-operation rates and complication rates after total laparoscopic hysterectomy (TLH) and laparoscopy-assisted supracervical hysterectomy (LASH). Eur J Obstet Gynecol Reprod Biol 158:269-273

9. Morelli M, Caruso M, Noia R, Chiodo D, Cosco C, Lucia E (2007) Total laparoscopic hysterectomy versus vaginal hysterectomy: a prospective randomized trial. Minerva Ginecol 59(2):99-105

10. Ng CC, Chern BS, Siow AY (2007) Retrospective study of the success rates and complications associated with total laparoscopic hysterectomy. J. Obstet. Gynaecol Res 3(4):512-518

11. Reich $H$, Roberts $L$ (2003) Laparoscopic hysterectomy in current gynaecological practice. Rev Gynaecol Pract 3:32-40

12. Ghezzi F, Uccella S, Cromi A, Siesto G, Serati M, Bogani G (2010) Postoperative pain after laparoscopic and vaginal hysterectomy for benign gynecologic disease: a randomized trial. Am J Obstet Gynecol 203(118):e1-e8

13. Pillet MCL, Leonard F, Chopin N, Malaret JM, Borghese B, Foulot H et al (2009) Incidence and risk factors of bladder injuries during laparoscopic hysterectomy indicated for benign uterine pathologies: a 14.5 years experience in a continuous series of 1501 procedures. Hum Reprod 24(4):842-849

14. Karacan T, Ozyurek E, Usta T, Odacilar E, Hanli U, Kovalak E, Dayan H (2018) Comparison of barbed unidirectional suture with figure-of-eight standard sutures in vaginal cuff closure in total laparoscopic hysterectomy. J Obstet Gynaecol 24:1-6. https://doi.org/10.1080/01443615.2017.1416597

15. Jacoby VL, Autry A, Jacobson G, Domush R, Nakagawa S, Jacoby A (2009) Nationwide use of laparoscopic hysterectomy compared with abdominal and vaginal approaches. Obstet Gynecol 114:1041-1048

16. Cui RR, Wright JD (2016) Risk of occult uterine sarcoma in presumed uterine fibroids. Clin Obstet and Gynecol 59:103-118

17. Wattiez A, Soriano D, Cohen SB, Nervo P, Canis M, Botchorishvili R (2002) The learning curve of total laparoscopic hysterectomy: comparative analysis of 1647 cases. J Am Assoc Gynecol Laparosc 9:339-345

18. Malzoni M, Perniola G, Perniola F, Imperato F (2004) Optimizing the total laparoscopic hysterectomy procedure for benign uterine pathology. J Am Assoc Gynecol Laparosc. 11:211-218

19. Thoma V, Salvatores M, Mereu L, Chua I, Wattiez A (2007) Laparoscopic hysterectomy: technique, indications. Ann Urol (Paris) 41:80-90

20. Maheux-Lacroix S, Lemyre M, Couture V, Bernier G, Laberge PY (2015) Feasibility and safety of outpatient total laparoscopic hysterectomy. JSLS 19:1-6

21. Donnez O, Jadoul P, Squifflet J, Donnez J (2009) A series of 3190 laparoscopic hysterectomies for benign disease from 1990 to 2006: evaluation of complications compared with vaginal and abdominal procedures. BJOG 116:492-500

22. Uccella S, Ghezzi F, Mariani A, Cromi A, Bogani G, Serati M, Bolis P (2011) Vaginal cuff closure after minimally invasive hysterectomy: our experience and systematic review of the literature. Am J Obstet Gynecol 205(119e):1-12

23. Uccella S, Cromi A, Bogani G, Casarin J, Formenti G, Ghezzi F (2013) Systematic implementation of laparoscopic hysterectomy independent of uterus size: clinical effect. J Minim Invasive Gynecol 20:505-516

24. Uccella S, Malzoni M, Cromi A, Seracchioli R, Ciravolo G, Fanfani F, Shakir F, Gueli Alletti S, Legge F, Berretta R, Corrado G, Casarella L, Donarini P, Zanello M, Perrone E, Gisone B, Vizza E, Scambia G, Ghezzi F (2018) Laparoscopic vs transvaginal cuff closure after total laparoscopic hysterectomy: a randomized trial by the Italian Society of Gynecologic Endoscopy. Am J Obstet Gynecol 218(5):500.e1-500.e13. https://doi.org/10. 1016/j.j.jog.2018.01.029

25. Bogliolo S, Musacchi V, Dominoni M, Cassani C, Gaggero CR, De Silvestri A, Gardella B, Spinillo A (2015) Barbed suture in minimally invasive hysterectomy: a systematic review and meta-analysis. Arch Gynecol Obstet 292(3):489-497

\section{Submit your manuscript to a SpringerOpen ${ }^{\circ}$ journal and benefit from:}

- Convenient online submission

- Rigorous peer review

- Open access: articles freely available online

- High visibility within the field

- Retaining the copyright to your article

Submit your next manuscript at $\boldsymbol{\nabla}$ springeropen.com 